Barton W. Evermann described the spawning habits of the Blueback and the Chinook Salmon, species which had been especially investigated by him during 1894 and 1895. These species have important spawning grounds at the headwaters of the Salmon and Payette rivers in Idaho. This paper gave an account of the manner in which the investigations were conducted and a statement of the more important results obtained.

These two species of salmon are, of course, anadromous, living in the sea, and entering fresh water only for spawning purposes. They enter the Columbia from the sea in the early spring and reach the headwaters of Salmon River over 1,000 miles from the sea, about the last week in July. The spawning began about the middle of August and continued for fully a month.

It has long been known that at spawning time these salmon have their fins more or less worn out and their bodies covered with mutilations, and these injuries were believed to have been received while on the long journey to the spawning grounds. But this was proved not to be true. More than 2,000 salmon were examined as they arrived upon the spawning beds and not one showed any mutilations of any kind.

As the spawning advanced the fish began to show mutilations; the caudal, anal and ventral fins became badly worn, and often the dorsal fin and the sides of the back were injured. By the time the spawning was at its height, scarcely a fish was wholly free from mutilations. The fish were observed daily during the entire spawning period and it was discovered that all the mutilations were received while on the spawning beds, chiefly in moving the gravel of the spawning beds about, but to some little extent in personal encounters between the males.

The second important fact determined was that, after spawning, the salmon coming to that region die, none of them ever returning to the sea. They began dying soon after they had done spawning. On September 7th 1,100 redfish or blue-back salmon were counted in the inlet to Alturas Lake. On September 16 th only 213 were left, and on September 22d there were scarcely any left. None had been caught out of the stream, but all had died. The fish showed no tendency to return down stream.

$$
\begin{aligned}
& \text { F. A. LucAs, } \\
& \text { Secretary. }
\end{aligned}
$$

ENTOMOLOGICAL SOCIETY OF WASHINGTON, APRIL 11, 1896.

THE 116th regular meeting was held in Baltimore on invitation of Mr. P. R. Uhler. Mr. Howard exhibited specimens of Margarodes vitium Giard, from South Africa. The locality is a new one, as the species has previously been found only in Chile and Argentina. Referring to a recent note by Valery Mayet, Mr. Howard suggested that the insect is now likely to be carried to many parts of the world in any earth which may occur around exported plants. Mr. Schwartz exhibited specimens of Coleocerus marmoratus and an undescribed Tychius, to illustrate two modes of variation brought about by different position and development of the scales. In the Coleocerus, some specimens are uniformly covered with large white scales, which in others are replaced in spots by brown scales of smaller size. In the Tychius some specimens have the elytra variegated with spots and lines composed of large white scales; in other specimens the positions which should be occupied by these scales are covered with a spongy mass which a high magnifying power shows to be composed of the white scales in a collapsed or undeveloped condition. In these specimens the development of the scales has apparently been arrested. Mr. Schwarz also exhibited a new Apion and two species of Anthonomus, one new and the other A. leucostictus Dietz, which he had reared from the seeds of Xanthoxylum pterota, at San Diego, Texas.

Dr. Henry Skinner, of Philadelphia, read a paper embodying his views on specific values, and illustrated his remarks with many examples drawn from the Rhoyalocera, insisting that morphological species are tentative and must be tested by a study of the life history and geographical distribution.

Mr. Ashmead read a paper on the genera Stephanus, Megischus and Megalyra and their position in the Hymenoptera, concluding that the family Stephaidæ does not deserve family rank and that the three genera should be 
placed among the Braconidæ in a subfamily which he called Setphaninæ.

Mr. Uhler made some remarks on the 'schlussfeld ' of certain Cicadidæ, tracing the development of this basal fold in the hind wings throughout Cicadas from many parts of the world and suggesting its connection with the rapidity of flight of the species. Mr. Benton spoke of the proposed introduction of Apis dorsata into the United States, giving an account of previous attempts and particularly of his own journey some years ago to Ceylon in search of this giant bee of India. He described the methods by which he secured colonies and gave an account of the habits of the bee and the character of its nests. He desired the opinion of the Society as to the possibility of the successful introduction of this bee into the United States and the desirability of such introduction. The paper was briefly discussed by Messrs. Mann, Skinner, Schwarz, Ashmead and Stiles.

L. O. HowaRD, Secretary.

\section{NEW YORK SECTION OF THE AMERICAN CHEMICAL SOCIETY.}

AT the meeting of the Section held on the 10th inst, at the College of the City of New York, Prof. Birchmore exhibited on the screen the absorption spectra of a number of aniline and other colors, including eosin, aniline red ultramarines, potassium permanganate, cudbear, etc., and explained the effect of certain reactions with ammonia and other reagents on the size and position of the absorption bands.

Dr. Birchmore also explained an arrangement of adjustable colored prisms projecting through the opposite sides of a cylinder, to be filled with a liquid having the same refractive index as glass : oil of juniper was mentioned; whereby the colors of the Nessler reagent in ammonia determinations could be recorded.

The description of this apparatus was brought out in the discussion of Dr. Albert R. Leeds' paper on 'Standard Prisms in Water Analysis, and the Valuation of Color in Potable Waters,' in which Dr. Leeds described his first attempts nearly twenty years ago to obtain suitable standards of comparison, using solutions of various kinds, colored glass plates and colored glass prisms. He reviewed the progress which has been made in the matter, and recommended the appointment of a committee to unify the methods and adopt a standard.

Prof. C. L. Speyers read a paper on 'Matter and Energy,' in which he discussed the more recent views of Ostwald.

Dr. E. G. Love exhibited some remarkably fine microphotographs of several varieties of starch.

Dr. L. Saarbach exhibited an improved form of laboratory temperature regulator, which has not only the advantage of small cost, but can be taken apart, cleaned and adjusted with the greatest ease. It may be arranged for high or low temperatures and for almost any degree of sensitiveness. It is practically an air thermometer, but can be adjusted to different degrees of sensitiveness by replacing more or less air, by mercury.

Prof. Breneman, chairman of the committee appointed to consider the organization of a chemical club, reported that he had received nearly a hundred replies to the circular sent out, all but about twenty of which were unqualifiedIy in favor of the project. He stated that there had been a misunderstanding on the part of some as to the intended membership, and he desired to have it known that there is no intention of limiting the membership to any society or section of the chemical fraternity, but to include chemists and chemical manufacturers generally.

Durand Woodman, Secretary.

GEOLOGICAL CONFERENCE OF HARVARD UNIVERSITY, MARCH 31, 1896.

'Longshore Transportation on the North Jersey Coast. J. Edmund Woodman.

Littoral transportation is caused by wind waves, wind currents, tidal waves and tidal currents. 'All these factors are in active operation on the Jersey coast, but the proof is very strong that the controlling forces are tidal. The most general statement of this proof is that the winds, which must be uniform over a considerable extent of shore, act in some places in conjunction with the transportation, in others in opposition to it.

From the region east of Toms river to Sandy 